\title{
ACCELERATION MEASUREMENT OF ROAD VEHICLES BY MOBILE PHONE
}

\author{
Atanas Ivanov \\ Faculty of Engineering and Pedagogics of Sliven, \\ Technical University of Sofia, Bulgaria \\ 59, Burgas Road str., 8800, Sliven, Bulgaria \\ e-mail: yovchev.ood@abv.bg
}

\begin{abstract}
The paper reviews existing solutions for the application of an acceleration sensor built into a mobile phone. A drawback of the results published in the available literature is that the experimental studies are performed in laboratory conditions and that high-complexity procedures and algorithms are used. It is necessary to perform field surveys, taking into account the factors influencing the measurement of the acceleration with a mobile phone. The studies and results obtained are complementary to those available from the literature in that the measurements are made "on the road". Factors that influence measurement accuracy in real-life conditions are defined. The results obtained show that mobile phones, regardless of brand and model, should be used to make such measurements and comparisons before being used for such purposes in order to make objective results and conclusions in scientific developments.
\end{abstract}

Keywords: Acceleration measurement, mobile phone, road vehicle.

\section{INTRODUCTION}

One of the main issues in each scientific study is the type and characteristics of the measuring equipment used. Depending on these characteristics, the degree of reliability of the results is subsequently determined. In recent years, with the development of technology, many of the quantities whose measurement previously required complex, bulky and expensive apparatuses can now be counted with mobile-integrated sensors $[2,3,4,6]$.

Bruwer et al. [1] offer a solution to the problem of using a mobile phone accelerometer by compensating for its deviations by adding a Kalman filter. Small acceleration values can be measured through this solution.

Monteiro et al. [5] offer the use of additional sensors - a gyroscope and an angular variance measuring device to measure small accelerations and compensate for the measurement error with an accelerometer from a mobile phone.

A drawback of the results published in the available literature is that the experimental studies are performed in laboratory conditions and that high-complexity procedures and algorithms are used. It is necessary to perform "on the road" surveys, taking into account the factors influencing the measurement of the acceleration with a mobile phone.

The aim of the report is to analyze the possibility of using a mobile phone acceleration sensor in a vehicle in real operating conditions.

\section{MATERIAL AND METHODS}

The materials and methods used include a description of the software and equipment, the location and the measurement conditions, the stages of planning and realization of the experiment; tasks of the team. 


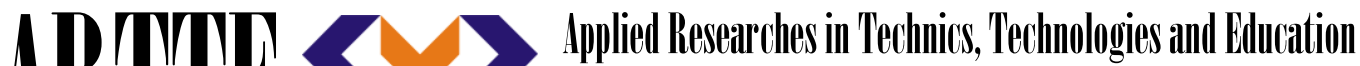 Journal of the Faculty of Technics and Technologies, Trakia University https://sites.google.com/a/trakia-uni.bg/artte/}

\subsection{Software and hardware tools used in the study}

- Iveco brand bus, model "Poker" produced by FIAT Spa;

- Mobile phone brand "HUAWEI" model "Y5i" production of "HUAWEI" China;

- Application software Sensor kinetics Pro, Version 3.1.2. Inovations, Inc .;

- Radar brand "Bushnell", producer "Bushnell" Inc. 9200 Cody Overland Park, KS.

\subsection{Place, conditions and technical tools}

Experimental Verification of acceleration measurement results with mobile phone HUAWEI Model Y5i, operating with Android operating system for research use: For the purposes of the present study, such an application for a mobile telephone "HUAWEI" is used. However, when looking at the first results of the acceleration measurement with the HUAWEI model $\mathrm{Y} 5 \mathrm{i}$, we noticed that the relative values of the measured results are very high and are in the range of 2,5 to $4,5 \mathrm{~m} / \mathrm{s}^{2}$.

The analyzed studies are by bus and the characteristics of these types of motor vehicles do not imply such high values. Additionally, counter-checks through experimentally recorded data such as time and speed showed a drastic discrepancy between actual and reported accelerations.

For this reason, other experimental measurements are made that we compared with the phone readings to make sure our future developments based on the use of this type of application with this brand of phones. Such an inspection would provide security and confidence in the results obtained in the future and the research and development related to acceleration reporting. For this purpose, we set out to determine under what conditions and parameters measurements with this type of meter are real or closest to those obtained from a standard instrument.

\subsection{Design of experiments}

Measurement of the acceleration motion from $\mathrm{V}_{0}=0$ to a certain speed, for example $\mathrm{V}=30$ $\mathrm{km} / \mathrm{h}$, while measuring the time to reach that speed and also the time passed for cross-check of the result. From the formula $\mathrm{a}=\mathrm{dV} / \mathrm{dt}$ the average acceleration can be determined. The experimental results are tabulated and the results of the phone that were in the CSV file format were imported into MS Excel.

\subsection{Experiment realization}

On a low-loaded, dry flat asphalt road, are plotted a section of $70 \mathrm{~m}$ in $5 \mathrm{~m}$. Length measurements are made with a device used to measure distances when analyzing road traffic accidents. The initial (starting line) from which the car leaves with $V_{0}=0 \mathrm{~km} / \mathrm{h}$ was noted. For the purposes of the experiment, a Bushnell radar brand was used, which is tared by the Road Traffic Control (Traffic Police) radar every year. The stopwatch that was used is electronic by a cell phone. The experiment involves 4 persons, two of them are in a car and two on a pitch of about $80-90 \mathrm{~m}$ from the starting line. 

https://sites.google.com/a/trakia-uni.bg/artte/

\subsection{Tasks of the driver}

One of the people in the car is a driver, his tasks by alerting the persons on the ground that the team in the car is ready to start the measurement. Measurement includes the following elements:

- Driving a vehicle with an acceleration of 0 to 30,40 and $50 \mathrm{~km} / \mathrm{h}$;

- Measurement of the acceleration by a phone in the car.

\subsection{Tasks of the second member of the team in the car}

- Start measurement of the phone's accelerations when triggering a beep;

- Stop the measurement of the phone when an experiment is terminated;

- Record the distance traveled by an end-of-experiment signal by visualizing the length of the path.

\subsection{The team on terrain}

The team on terrain, consisting of two people has the following tasks:

- One of the persons measures radar speed, signals a start by dropping from the vertical to horizontal position of the radar, and gives an end-of-experiment signal when it reaches the specified speed by lowering the radar vertically downwards;

- The second member of the team starts and stops the stopwatch of the alerts so described, and also records the results of the experiment.

\subsection{Order of performance measurements}

The vehicle is positioned in the starting position. Upon receiving a signal from the driver, the measuring speed rises vertically up the radar. When moving forward to a horizontal position, the following actions occur:

- The stopwatch on terrain is turned on;

- The accelerometer inside the vehicle is turned on;

- The car accelerates and retains its own movement until the end of the experiment. Upon reaching the pre-planned speed (for example, $40 \mathrm{~km} / \mathrm{h}$ ), the hand of the person holding the radar drops down sharply, indicating the end of the experiment. At this point, the following actions take place:

- Turn off the stopwatch;

- Turn off the accelerometer;

- The length of the time traveled for the time of the experiment is visually measured.

The vehicle stops at the field team and the results are recorded in a table (the time elapsed, the time and speed remaining on the radar display), and the accelerometer results are imported into an email with the corresponding experiment number.

\section{RESULTS AND DISCUSSION}

Initially, nine measurements were made with three reps at speeds of 30,40 and $50 \mathrm{~km} / \mathrm{h}$. The results of the experiment are presented in Table 1.

Figure 1 shows the acceleration chart of a vehicle in the first measurement. It appears that the acceleration gradually increases at the beginning of the measurement. Then gear and stop switching is counted from the mobile phone's accelerometer. 


\section{IRTITE}

Ipplied Researrches in Technics, Technologies ind Educition Journal of the Faculty of Technics and Technologies, Trakia University https://sites.google.com/a/trakia-uni.bg/artte/

Table 1. Results of first measurement

\begin{tabular}{|c|c|c|c|c|}
\hline $\begin{array}{c}\text { Speed, } \\
\mathrm{km} / \mathrm{h}\end{array}$ & Time, $\mathrm{s}$ & Distance, $\mathrm{m}$ & $\begin{array}{c}\text { Mean reference } \\
\text { acceleration, } \mathrm{m} / \mathrm{s}^{2}\end{array}$ & $\begin{array}{c}\text { Mean acceleration from } \\
\text { mobile phone, } \mathrm{m} / \mathrm{s}^{2}\end{array}$ \\
\hline $0-30$ & 3,81 & 45 & 2,18 & Unsuccessful \\
\hline $0-30$ & 2,95 & 35 & 2,82 & 7,25 \\
\hline $0-30$ & 3,39 & 35 & 2,45 & 6,33 \\
\hline $0-40$ & 5,97 & 45 & 1,86 & 6,14 \\
\hline $0-40$ & 4,47 & 45 & 2,48 & 6,12 \\
\hline $0-40$ & 4,18 & 40 & 2,65 & 5,97 \\
\hline $0-50$ & 5,05 & 50 & 2,85 & 5,85 \\
\hline $0-50$ & 5,39 & 60 & 2,67 & Unsuccessful \\
\hline $0-50$ & 5.21 & Unsuccessful & 2,77 & Unsuccessful \\
\hline
\end{tabular}

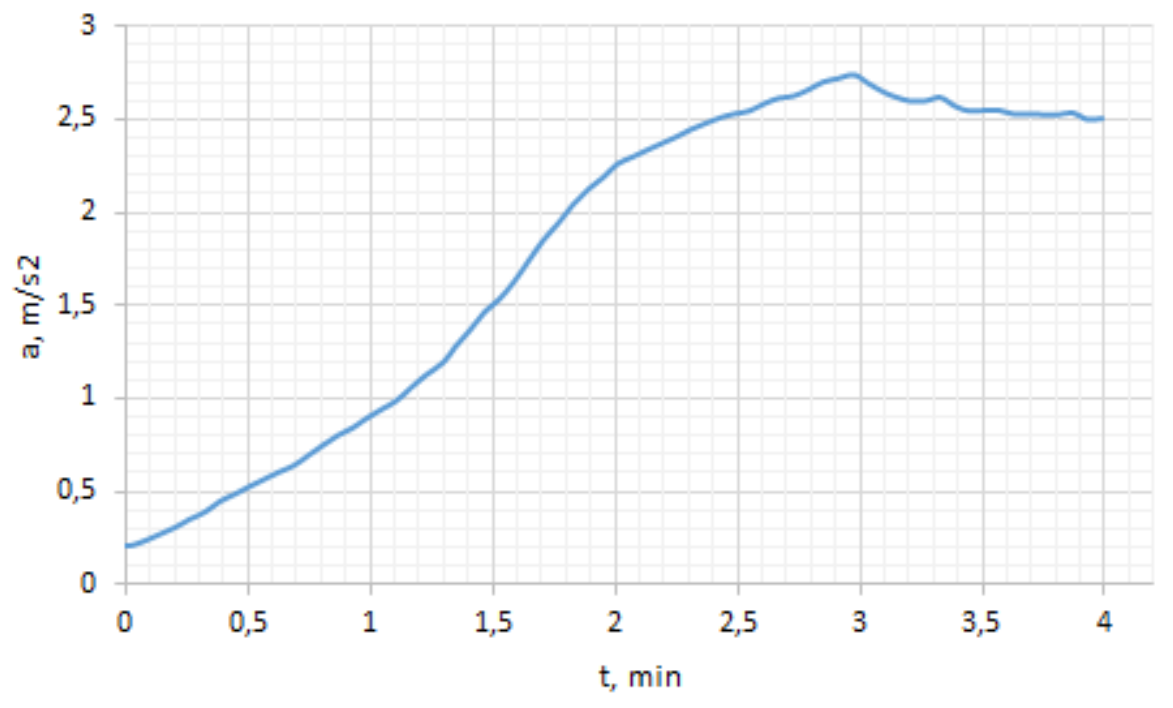

Figure 1. Car acceleration chart for first measurement

Using the acceleration formula $a=V / t$, first the velocity is converted to $\mathrm{km} / \mathrm{h}$. In $\mathrm{m} / \mathrm{s}$ with the formula $1 \mathrm{~km} / \mathrm{h}=1000 \mathrm{~m} / 3600 \mathrm{~s}$. With $8,3 \mathrm{~km} / \mathrm{h}$ at $40 \mathrm{~km} / \mathrm{h} ; 11,1 \mathrm{~m} / \mathrm{s}$, and at $50 \mathrm{~km} / \mathrm{h}$ respectively $14,44 \mathrm{~m} / \mathrm{s}$. Thereafter, the velocity and time of each test were calculated and the average acceleration for each test was obtained. Every sampling attempt corresponds with the sensor measurement of the mobile phone, which is processed with an averaging function in MS Excel.

Due to a discrepancy between the experimental and the phone's sensor results, the experiment was repeated as some of the parameters and performance conditions were refined. After analyzing the overall performance of the experiment, we came to the conclusion that the position of the phone needs to be fine-tuned. The sensor axes in the phone must match the axes of gravity and the direction of movement of the vehicle. The position of the phone was judged so that at zero acceleration the two graphs on $X$ and $Y$ would be on the abscissa axis. to report 0 , and $Z$ to report exactly $9,8 \mathrm{~m} / \mathrm{s}^{2}$.

The speedometer (radar) readings are recorded and the actual speed is recorded until the end. For example, the speed is measured up to $50 \mathrm{~km} / \mathrm{h}$, but the radar has a sealed speed of $52 \mathrm{~km} / \mathrm{h}$. Calculations were made at $52 \mathrm{~km} / \mathrm{h}$ instead of $50 \mathrm{~km} / \mathrm{h}$ in the initial measurements. The driver also visually monitors the distance traveled, and in case of hesitation between him and the person working with the phone, he averaged the result indicated by them. The new 9 measurements are recorded in Table 2.

IRTIIE Vol. 7, No. 2, 2019 ISSN 1314-8788 (print), ISSN 1314-8796 (online), doi: 10.15547/artte.2019.02.002 


\section{IRTITE}

Ipplied Researroches in Technics, Technologies and Bducation

Journal of the Faculty of Technics and Technologies, Trakia University https:///sites.google.com/a/trakia-uni.bg/artte/

Table 2. Results of first measurement

\begin{tabular}{|c|c|c|c|c|}
\hline Speed, $\mathrm{km} / \mathrm{h}$ & Time, s & Distance, $\mathrm{m}$ & $\begin{array}{c}\text { Mean } \\
\text { Mean reference } \\
\text { acceleration, } \mathrm{m} / \mathrm{s}^{2}\end{array}$ & $\begin{array}{c}\text { acceleration } \\
\text { from mobile } \\
\text { phone, } \mathrm{m} / \mathrm{s}^{2}\end{array}$ \\
\hline $0-30$ & 4,25 & 30 & 1,96 & 2,15 \\
\hline $0-30$ & 4,26 & 20 & 1,95 & 1,69 \\
\hline $0-30$ & 4,31 & 25 & 1,93 & 2,17 \\
\hline $0-40$ & 5,89 & 40 & 1,88 & 2,13 \\
\hline $0-40$ & 5,95 & 45 & 1,86 & 2,09 \\
\hline $0-40$ & 6,22 & 45 & 1,78 & 2,15 \\
\hline $0-52$ & 5,29 & 47,5 & 2,73 & 2,91 \\
\hline $0-52$ & 6,01 & 55 & 2,40 & 2,23 \\
\hline $0-54$ & 5,03 & 45 & 2,98 & 3,37 \\
\hline
\end{tabular}

Figure 2 shows the acceleration chart of a vehicle in a second measurement. There are four types of suspected comfort disturbances such as rapid braking, lateral acceleration, pumping and thrust.

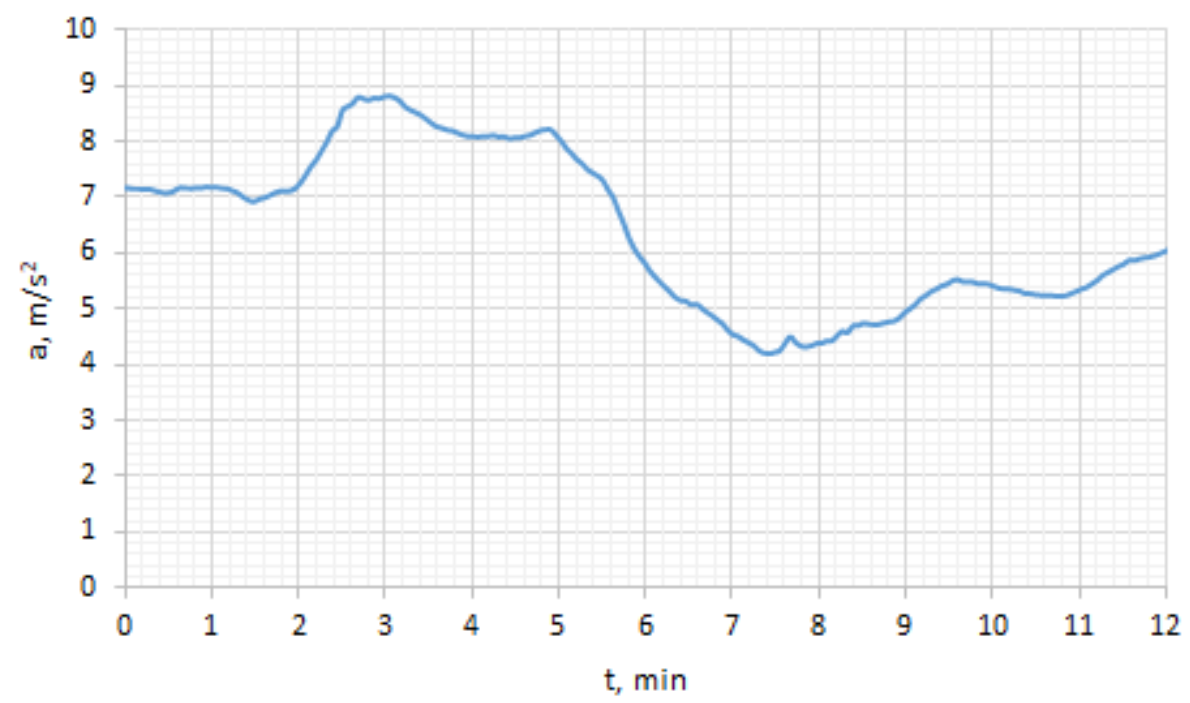

Figure 2.

Car acceleration chart for second measurement

The results of the second measurements after the refinements in the measurement conditions give grounds to assert that the results obtained are reliable. The differences with the results of the experiments are negligible. In our opinion, they are due to inaccuracies in natural measurements and not to errors in the sensor on the phone.

Some preliminary deficiencies can be identified from the preliminary studies that have been carried out, without neglecting the fact that some of the reasons are due to the need for the driver to comply with the driving situation. 


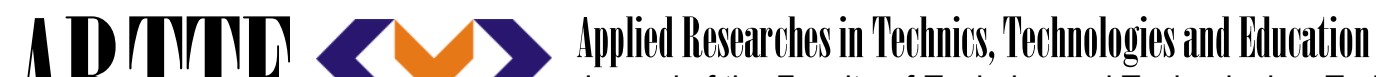 Journal of the Faculty of Technics and Technologies, Trakia University https://sites.google.com/a/trakia-uni.bg/artte/}

\section{CONCLUSION}

As a result of the experimental measurements, it has been found that the use of mobile sensors in the field of acceleration measurement research is possible and justified. In practical use of the acceleration sensor, the phone should be positioned correctly, at least in the initial position when the measurements begin, for the measurement to be credible.

It will be good, before using for such purposes, mobile phones, regardless of brand and model, to make such measurements and comparisons to make objective results and conclusions in scientific developments.

\section{REFERENCES}

[1] Bruwer F., M. Booysen. (2015). Vehicle acceleration estimation using smartphone-based sensors. Proceedings of the 34th Southern African Transport Conference (SATC 2015), pp. 118-129.

[2] Elnashar E., Z. Zlatev. (2018). Analysis of Data from Software Sensor for Smart Airbags Deployment. Advances in Robotics \& Automation, Vol. 7, Issue 1, ISSN: 2168-9695, pp. 1-6.

[3] Engelbrecht J., M. Booysen, G. van Rooyen. (2014). Recognition of Driving Manoeuvres using Smartphone-Based Inertial and GPS Measurement. Proceedings of the First International Conference on the Use of Mobile Informations and Communication Technology (ICT) in Africa UMICTA. STIAS Conference Centre, Stellenbosch: Stellenbosch University, Department of Electrical \& Electronic Engineering, South Africa. 9-10 December 2014.

[4] Kotseva I., M. Gajdarova, K. Angelov. (2017). Smartphones as a Tool for Measurement and Visualization in Physics Education. Engineering and Science Education, Vol.2, Issue 1 (in Bulgarian).

[5] Montero M., C. Cabeza, A. Marti. (2015). Acceleration measurements using smartphone sensors: dealing with the equivalence principle. Revista Brasileira de Ensino de Fisica, Vol. 37, No.1, pp.1303-1-1303-6.

[6] Karapetkov, S., Z. Kalitchin, H. Uzunov. (2002). Determination of Vehicles' Velocities in CarCrash Using Different Friction Coeffiecients. 4th International Conference on Tribology, Kayseri, Turkey, 12-14 June, 2002, Proceedings, Volume II, pp. 455-463. 